\title{
Metabolism of riboflavine in germ-free and conventional rabbits
}

\author{
BY E. C. OWEN AND D. W. WEST \\ Biochemistry Department, Hannah Dairy Research Institute, Ayr \\ AND MARIE E. COATES \\ Nutrition Department, National Institute for Research in Dairying, \\ Shinfield, Reading \\ (Received ro fune 1969-Accepted 22 September 1969)
}

\begin{abstract}
I. Isoalloxazines were characterized and measured in the caecum of two conventional rabbits kept on an adequate diet, two rabbits on the same diet from which vitamin $B_{2}$ (riboflavine) had been omitted and five germ-free rabbits which were also on the adequate diet.

2. Riboflavine (up to $12 \mathrm{mg}$ ) unaccompanied by any of its degradation products was found in the caecum of germ-free rabbits and 8 $-9 \mu \mathrm{g}$ per $\mathrm{ml}$ were found in their urine.

3. Hydroxyethylflavine $(4-5 \mathrm{mg})$ accompanied only by traces of riboflavine was found in the caecum of conventional rabbits.

4. There was about $\mathrm{I} \%$ ash in the contents of each of five germ-free and two conventional caecums.

5. The five germ-free caecal contents averaged $22.4 \%$ of the animal's body-weight. For four conventional animals this figure was only $10.5 \%$.

6. In the caecum of each of two conventional rabbits kept on a diet deficient in riboflavine neither riboflavine nor hydroxyethylflavine was found but there was somewhat less than I $\mathrm{mg}$ of a yellow-fluorescing material of low $R_{F}$ value in each caecum.

7. 'The results are discussed in relation to the authors' previous reports on metabolites of riboflavine.
\end{abstract}

Degradation products of riboflavine (vitamin $B_{2}$ ) in the animal body were unknown till Owen $(1962 a, b)$ isolated from the urine of the goat a metabolite of riboflavine and identified it as 7,8-dimethyl-Io-( 2 '-hydroxyethyl)isoalloxazine (HEF). In the course of the same experiments he showed that this substance could be demonstrated in rumen contents and milk, and that in rumen contents, in milk and in urine it was accompanied by a number of other yellow-fluorescing metabolites of riboflavine. Later Owen \& West (1968, 1970) showed that some of these additional yellowfluorescing metabolites also had an intact isoalloxazine ring and one of them was identified as 7,8-dimethyl-ro(formylmethyl)-isoalloxazine (FMF). In later experiments Owen \& West (I970) showed that HEF and FMF and probably the other metabolites are also the products of definite species of bacteria normally inhabiting the alimentary tract (Hobson, Summers, Owen, Spencer \& West, 1969) and that such metabolites can be demonstrated in the urine of man (West \& Owen, 1969) and rabbit but not in that of the dog when gram quantities of the vitamin are eaten by these species. The experiments of Owen \& West (1970) showed that liver and kidney can convert FMF to HEF and also that riboflavine and HEF are subject to enterohepatic recycling.

Ruminants can live on diets devoid of all the water-soluble vitamins and of vitamin 
$\mathrm{K}$ because these substances are synthesized by micro-organisms in the rumen (McElroy \& Goss, I94I). In an analogous manner, by their habit of coprophagy, rabbits and rats obtain water-soluble vitamins formed by micro-organisms in the hind-gut. Thus Olcese, Pearson \& Schweigert (1948) showed that riboflavine is not an essential nutrient for the conventional rabbit.

Micro-organisms become established in those parts of the gut where the passage of food is delayed; hence the rumen, caecum and colon are major sites of microbial activity. In chicks reared on a diet devoid of riboflavine, Coates, Ford \& Harrison ( 1968 ) found by microbiological assay $16 \cdot 3 \mu \mathrm{g}$ riboflavine in the caecal contents of conventional birds and none in the caecal contents of comparable germ-free birds.

In the experiments now reported the metabolism of riboflavine in the caecum of a group of germ-free rabbits was compared with that of conventionally reared controls, both groups being fed the same purified diet in which crystalline riboflavine was the sole source of the vitamin. In addition two conventional rabbits were fed on the same diet with riboflavine omitted.

\section{EXPERIMENTAL}

There were two experiments. In Expt I a comparison was made between germ-free and conventional rabbits, all on diets containing riboflavine. In Expt 2 the diet was riboflavine-deficient.

Animals. The rabbits of Expt I were the progeny of New Zealand White does mated with New Zealand White or Chinchilla bucks. The rabbits of Expt 2 were New Zealand Whites, 4 months old, from the stock colony. The germ-free animals were delivered by hysterectomy approximately I day before term into Gustafsson stainless steel isolators. The conventional controls were born naturally but immediately removed from the doe into a room in which the temperature, humidity and lighting could be controlled to

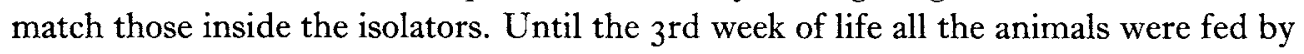
hand on a diet of cow's milk, fortified with $5 \%$ casein and a vitamin supplement, sterilized by an ultra-high-temperature process. After this period they were gradually introduced to the experimental diet which was fed first as a paste and then as pellets. By the $5^{\text {th }}$ to 6 th week of age they were fully weaned on to the pelleted diet. All the rabbits were kept in screen-bottomed cages, but with rabbits this method of housing does not prevent coprophagy (Olcese et al. 1948).

Diets. Diet I, which was fed to rabbits I-5, was similar to that of Moore \& Williams (1964) and had the percentage composition: maize oil 20 , wheat starch 15.8 , sucrose Io, casein 25 , wood cellulose 19 , methylcellulose I, potassium acetate 2.5 , magnesium oxide, 0.5 , sodium chloride 0.7 , choline chloride 0.5 , salt mixture 4 , vitamin mixture $r \cdot 0$. The salt mixture itself had the following composition: calcium lactate pentahydrate $3900 \mathrm{~g}$, ferric citrate trihydrate $355 \mathrm{~g}$, dipotassium monohydrogen orthophosphate $2862 \mathrm{~g}$, tricalcium orthophosphate $1620 \mathrm{~g}$, monosodium dihydrogen orthophosphate monohydrate $104 \mathrm{I}$ g, magnesium sulphate $798 \mathrm{~g}$, sodium chloride $5 \mathrm{I} 9 \mathrm{~g}$, cupric sulphate pentahydrate $15 \mathrm{~g}$, manganese sulphate tetrahydrate $60 \mathrm{~g}$, potassium iodide $\mathrm{I} \cdot 5 \mathrm{~g}$, zinc carbonate $\mathrm{I} \cdot 5 \mathrm{~g}$. The vitamin mixture was of the following composition: biotin $50 \mathrm{mg}$, folic acid $50 \mathrm{mg}, p$-aminobenzoic acid $35 \mathrm{~g}$, thiamine hydro- 
chloride $5 \mathrm{~g}$, riboflavine $5 \mathrm{~g}$, pyridoxol hydrochloride $5 \mathrm{~g}$, calcium pantothenate $5 \mathrm{~g}$, nicotinic acid $8 \mathrm{~g}$, meso-inositol I $5 \mathrm{~g}$, ascorbic acid $5 \mathrm{~g}$, cyanocobalamin $4 \mathrm{mg}$, menaphthone sodium bisulphite $750 \mathrm{mg}$, Rovimix E (250 $\mathrm{mg} \alpha$-tocopheryl acetate/g) $20 \mathrm{~g}$, Rovimix $\mathrm{AD}$ (50000 i.u. vitamin $\mathrm{A}$ and 5000 i.u. viamin $\mathrm{D}_{3} / \mathrm{g}$ ) $20 \mathrm{~g}$, glucose to $500 \mathrm{~g}$.

The fat content of diet I was higher than is usual in diets for rabbits because the animals were also being used to study certain aspects of lipid metabolism (to be reported elsewhere). Values were, however, obtained for two germ-free rabbits (nos. 6 and 7) given a diet (2) in which $19.5 \%$ of the maize oil was replaced by an equicaloric amount of wheat starch. The diets, both for germ-free and conventional animals, were sterilized by a dose of gamma radiation of $5 \mathrm{Mrad}$ from a ${ }^{60} \mathrm{Co}$ source. A sample of diet 2, assayed fluorimetrically after irradiation, contained $86 \mathrm{ppm}$ of riboflavine.

In Expt 2, conventional rabbits nos. 8 and 9 were given unsterilized diet (3), which was diet I with the riboflavine omitted.

Treatment of animals of Expt $\mathrm{I}$. The sterility checks recommended by Fuller (rg68) were applied at intervals to show that the germ-free animals remained free from detectable contaminants throughout the experiment. At the end of the experimental period, which lasted from 9 to 14.5 weeks, the animals were weighed and killed by gassing with ether. The caecum and its contents were removed, weighed and stored at $-20^{\circ}$ until the contents were analysed. From the germ-free rabbits nos. 5 and 7 urine samples were taken just before the animals were killed.

Treatment of animals of Expt 2. The riboflavine-deficient diet was first offered to the rabbits with some of their usual stock diet. The animals accepted it readily and after about a week were eating only the deficient diet. One rabbit lost condition and died I 8 days later; the second was killed in relatively good condition after $\mathrm{I}$ month on the experimental diet. A sample of its urine was collected just before it was killed.

Extraction of isoalloxazines from the caecal contents. In order to disintegrate bacterial cells and so to set free isoalloxazines, accurately weighed amounts (about $2 \mathrm{~g}$ ) of caecal contents were ground with sand in a mortar, after which $5 \mathrm{ml}$ trichloroacetic acid were added. Grinding was repeated and the sample was left for $15 \mathrm{~min}$ before being centrifuged at $2200 \mathrm{~g}$ for $\mathrm{r}_{5} \mathrm{~min}$. The supernatant fraction was filtered through glass wool into a measuring cylinder. The residue was washed and centrifuged till free from fluorescence, the washings being added to the mother liquor after each centrifugation. The extract was neutralized with $4 \mathrm{M}-\mathrm{K}_{2} \mathrm{H} \mathrm{PO}_{4}$ and left for $\mathrm{I}$ h. After the volume, which varied from 40 to $150 \mathrm{ml}$, had been recorded, the extract was filtered through a no. 24 Whatman filter-paper and its fluorescence was measured in a Locarte Fluorimeter with primary filter $\mathrm{LF}_{3}$ and secondary filter LF 7 (Owen \& West, I970). Accurate measurements down to $0.07 \mu \mathrm{g}$ riboflavine per $\mathrm{ml}$ can be made with this instrument.

Extraction of isoalloxazines from urine. Extractions were as described previously by Owen (1962a) and Owen \& West (1970).

Acetylation of isoalloxazines. Concentrates were taken to dryness in a rotatory evaporator and dissolved in $\mathrm{I} \mathrm{ml}$ pyridine in a stoppered tube. Acetic anhydride $(0.1 \mathrm{ml})$ was added and the tube was left overnight, after which methanol was added to inactivate the excess of acetic anhydride and the mixture was evaporated to a volume small 
enough to give spots or lines on thin-layer chromatographic plates which were readily visible by their yellow-fluorescence in long wave u.v. illumination.

Thin-layer chromatography. Thin-layer chromatography was on layers of silica gel (Kieselgel D5, Nagel and Co.) $0.25 \mathrm{~mm}$ thick on glass plates 10 to $20 \times 20 \mathrm{~cm}$. Part of each concentrate was applied as a band and part as discrete spots. As markers, spots of riboflavine, of hydroxyethylflavine and of their acetoxy derivatives were applied both separately and within the band or bands of the concentrate. In this way any unexpected effects of materials in the concentrates which might have affected the $R_{F}$, values were guarded against.

Three solvent systems were used, and during developments the glass tanks were kept in the dark to prevent photolysis of the isoalloxazines. The solvent systems were (A) chloroform-methanol $(9: \mathrm{I} ; \mathrm{v} / \mathrm{v})$ (B) benzene-pyridine-acetic acid $(4: \mathrm{I}: \mathrm{I} ; \mathrm{v} / \mathrm{v})$ and $(\mathrm{C})$ n-butanol-acetic acid-water $(4: \mathrm{I}: 5 ; \mathrm{v} / \mathrm{v}$; upper phase). After ascending development, plates were dried in the dark in a current of hot air and were then examined in long-wave u.v. light. These methods permitted the detection of about $0 \cdot \mathrm{I} \mu \mathrm{g}$ isoalloxazine per $\mathrm{g}$ caecal contents.

Mineral content of caecum. The percentage of ash in the caecal contents was found by ashing weighed amounts (about $5 \mathrm{~g}$ ) in duplicate, in weighed platinum basins. Initial combustion was over a luminous bunsen flame and was completed in an electric muffle furnace at $600^{\circ}$ overnight. After having been weighed, the ash was moistened with water, treated with a few drops of concentrated nitric acid, dried in an oven at $100^{\circ}$ and then heated again at $600^{\circ}$. After a further cooling and moistening, drying at $100^{\circ}$ and heating at $600^{\circ}$ the weight of the ash showed no change and was recorded.

RESULTS

Table I shows the $R_{F}$ values of riboflavine, of its tetra-acetoxy derivative, of hydroxyethylflavine and of its acetoxy derivative. Table I shows that by simultaneous testing with all three chromatographic systems (A), (B) and (C), above, and by using acetylation, riboflavine is readily distinguished from hydroxyethylflavine. The results of such

Table $\mathrm{I}_{\mathrm{F}} \mathrm{R}_{\mathrm{F}}$ values of isoalloxazines in solvent systems $(A),(B)$ and $(C)$ obtained from chromatography by upward development in thin layers of silica on glass sheets $10 \times 20 \mathrm{~cm}$

\begin{tabular}{|c|c|c|c|}
\hline Isoalloxazine & $\begin{array}{l}\text { (A), Chloroform- } \\
\text { methanol } \\
(9: 1 ; v / v)\end{array}$ & $\begin{array}{c}\text { (B), Benzene-pyridine- } \\
\text { acetic acid } \\
(4: 1: 1 ; \mathrm{v} / \mathrm{v})\end{array}$ & $\begin{array}{l}\text { (C), n-butanol-acetic } \\
\text { acid-water ( } 4: 1: 5 ; \\
v / v ; \text { upper phase) }\end{array}$ \\
\hline $\begin{array}{l}\text { Riboflavine } \\
\text { Tetra-acetoxy-riboflavine }\end{array}$ & $\begin{array}{l}0.10 \\
0.80\end{array}$ & $\begin{array}{l}0.10 \\
0.80\end{array}$ & $\begin{array}{l}0.45 \\
0.65\end{array}$ \\
\hline Hydroxyethylflavine & $0 \cdot 30$ & 0.25 & 0.55 \\
\hline Acetoxyethylflavine & 0.50 & 0.50 & 0.55 \\
\hline
\end{tabular}

testing and of certain other analyses are shown in Table 2. We have found that hydroxyethylflavine occurs in the urine of rabbits (West, Owen \& Taylor, 1967; Owen \& West, 1970) fed a diet of greenstuff from the leaves of weeds and grass, and (E. C. Owen \& D. W. West, unpublished) that no riboflavine is present with the 
Vol. 24

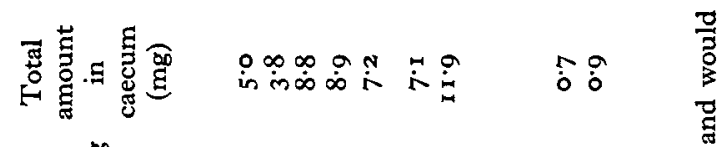

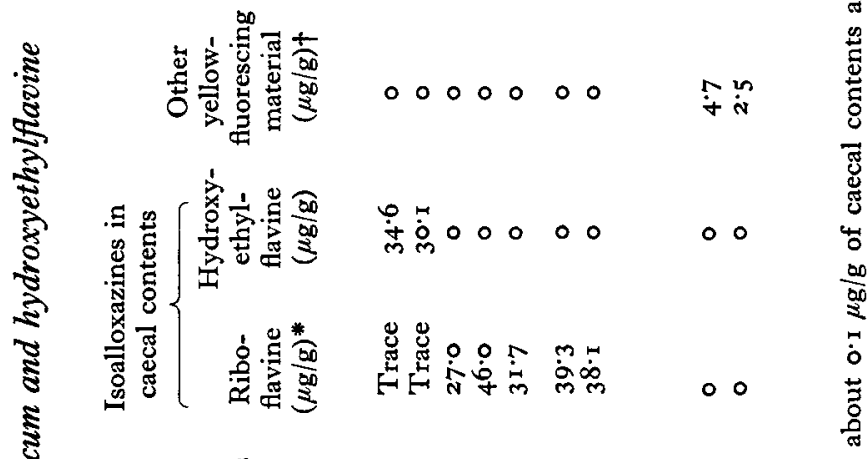

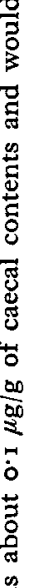

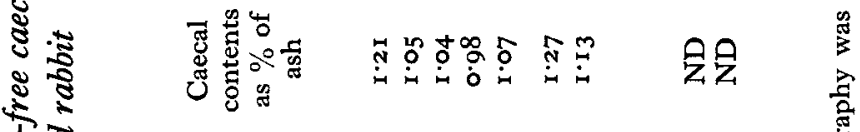

章

.

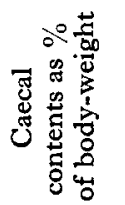

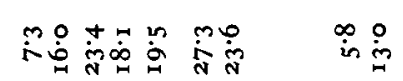

胥

.$\ddot{8} 8$

造

के

2 8

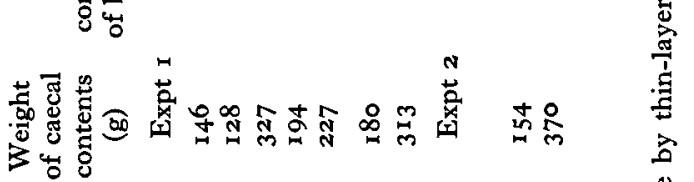

$\rightarrow$ दु

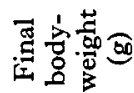

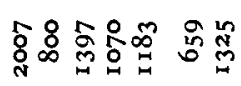

융유

s.

$\dot{0}$

8.

皮

$\$$

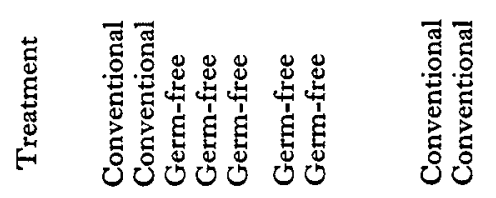

密

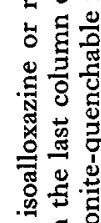

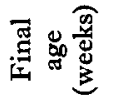

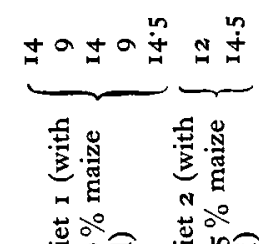

กล

넝

N

$\frac{0}{0}$

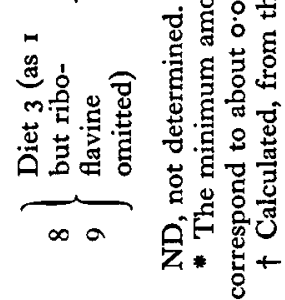


hydroxyethylflavine. The same kind of chromatogram resulted from the two conventionally treated rabbits nos. I and 2 (Table 2) which were eating the same diet I as that fed to the germ-free rabbits.

The most notable result in Table 2 is that whereas all the isoalloxazine in the caecum of the conventional rabbits nos. I and 2 was in the form of hydroxyethylflavine, in the caecum of each of the germ-free animals, nos. 3-7, only riboflavine was present. From the germ-free rabbits 5 and 7,18 and $\mathrm{i} \mathrm{ml}$ respectively of urine were collected just before death. These urines contained no metabolites, but only riboflavine.

The two conventionally managed rabbits, nos. 8 and 9 which were given the riboflavine-deficient diet 3 , showed neither riboflavine nor hydroxyethylflavine in the caecum. The last column in Table 2 shows that, of the caecal contents, only 0.7 and $0.9 \mathrm{mg}$ could have been isoalloxazines. These values, which are much less than those of any other of the animals, were calculated from the dithionite-quenchable fluorescence of the extracts of nos. 8 and 9. In neither of these caecums did the chromatograms show either riboflavine or hydroxyethylflavine in the concentrated extracts, whether they were tested directly or after acetylation with pyridine and acetic anhydride. The substance, the yellow fluorescence of which was quenched by sodium dithionite had an $R_{F}$ in system C relative to the $R_{F}$ of riboflavine between 0.08 and 0.12 so that it could have been a combined form of riboflavine such as flavine- 5 '-phosphate or flavine-adeninedinucleotide. Three blue-fluorescing bands were present, one extending from 0.7 to $0.8 R_{F}$, one from $R_{F} 0.9$ to $\mathrm{I} \cdot 0$, and a much narrower one remaining at the origin -0.25 to +0.25 . The urine of rabbit no. 9 likewise showed no chromatographic evidence of either riboflavine or hydroxyethylflavine. A blue- and a purplefluorescing material, of unknown identity, were also present as discrete bands in the urine of rabbits nos. 8 and 9.

In Table 2 the ratio of the weight of the caecal contents to the body-weight of each rabbit is shown and reveals that, in the germ-free animals, this ratio was always bigger than it was in any of the conventional animals. Calculation from Table 2 shows an average ratio of $10.5 \%$ for the conventional and $22.4 \%$ for the germ-free animals.

The percentage of ash in the caecal contents of rabbits nos. 1-7 (Table 2) was about $\mathbf{I} \%$ in every sample, but the significance of this equality cannot at present be assessed.

\section{DISCUSSION}

It is clear from the results in Table 2 that the form of riboflavine in the caecum was profoundly influenced by the presence of the gut microflora. Riboflavine, the sole dietary source of the vitamin, was the only isoalloxazine found in the caecums of germ-free rabbits whereas its hydroxyethyl catabolite accounted for most of the isoalloxazine in the conventional caecal contents. Furthermore, although in our earlier studies urine from conventional rabbits contained only hydroxyethylflavine (E. C. Owen \& D. $\mathrm{W}$. West, unpublished), the urine obtained from two germ-free rabbits in the present study contained, in contrast, only riboflavine. These findings support the hypothesis based on our earlier experiments with ruminants (Owen \& West, 1970, 1969) that hydroxyethylflavine is of microbial origin. 
It is possible that the riboflavine in the caecum of the germ-free animals represented the amount that had escaped absorption on passage through the alimentary tract, particularly as, in the absence of definitive knowledge of the riboflavine requirements of either conventional or germ-free rabbits, the diet contained a generous supplement. Whether the HEF in the conventional caecums had arisen from conversion of excess dietary riboflavine or had been formed by microbial synthesis could not be deduced from the results of Expt I. Quantitative comparison between animals in the two environments is complicated by the difference in caecal size. The phenomenon of an enlarged caecum in germ-free rodents and rabbits is well recognized, and it was not surprising that the caecums of the germ-free animals were about twice as heavy per unit of body-weight as those of their conventional counterparts (Table 2).

The rabbit habitually eats the faeces that it passes at night (Eden, I940, I941; Thacker \& Brandt, 1955). These night faeces differ visibly from the day faeces, are believed to be of caecal origin, and contain microbially synthesized vitamins which enable the animal to subsist on diets low in the B-vitamins (Kulwich, Struglia \& Pearson, 1953). It was therefore somewhat surprising that the total amount of isoalloxazine in the conventional caecum was no greater than in the germ-free, or that so little of it was true riboflavine. Olcese et al. (1948) reported that rabbits grew and reproduced satisfactorily on diets low in riboflavine and showed by balance studies that the amounts of riboflavine excreted exceeded the intake by many times. It was of some importance therefore to determine the extent of riboflavine synthesis by conventional rabbits on the diet used in these studies. Two stock conventional animals were accordingly given diet 3 , which was devoid of riboflavine, and their caecal contents were examined after 18 and 28 days respectively. The total caecal content of isoalloxazine was much less than that of the caecum from any of the germ-free or conventional animals given the complete diet and neither riboflavine nor HEF was detectable in the caecum of these diet 3 animals. Instead, small quantities of isoalloxazines of low $R_{F}$ were found, thus recalling the experiments of Innami \& Tezuka (1965) who found flavine-adenine-dinucleotide and flavine-mononucleotide but only traces of riboflavine in the caecums of rats.

Clearly, in the present state of knowledge the significance of the various forms of isoalloxazines in the caecum of rat or rabbit cannot properly be assessed.

Urine collected from the conventional animal kept for 28 days on the diet devoid of riboflavine likewise showed no evidence of either riboflavine or HEF, although other fluorescent substances were present.

Thus it seems reasonable to conclude that on the diet used in these experiments there was little if any microbial synthesis of riboflavine and that the isoalloxazine appearing in the caecum was unabsorbed riboflavine, which in the conventional animal had been degraded to HEF. Our failure to find evidence for the synthesis of riboflavine in conventional rabbits on a riboflavine-deficient diet is at variance with the finding of Olcese et al. (1948). The difference may be due to the different composition of our basal diet.

A further puzzling result of the present studies is the production in the rabbit of only one isoalloxazine metabolite, for there are at least three other isoalloxazine-like 
metabolites produced by ruminants and by man (Owen, 1962 $a, b$; West \& Owen, 1969). Possibly hepatic recycling in the rabbit coupled with its very efficient method of faecal recycling either limits the activities of caecal bacteria or causes other metabolites initially produced all to be changed into hydroxyethylflavine. We know that in the ruminant, hydroxyethylflavine can result from the action of kidney or liver enzymes on formylmethylflavine, one of the other ruminant metabolites of riboflavine. A further explanation may lie in the constitution of the normal gut flora. Bacteriological studies by Smith (1965) have shown that, in contrast to other homoiothermic species the rabbit has a limited number of types of organisms and a limited population of them in its alimentary tract: perhaps organisms capable of degrading riboflavine to metabolites other than HEF are absent (Hobson et al. 1969).

Our finding of small amounts of riboflavine in the urine of germ-free rabbits suggests that the level in the diet was in excess of the animal's requirement. Similarly, the considerable quantity of $\mathrm{HEF}$ in the caecum of each of the conventional rabbits implies that the diet supplied more riboflavine than was utilized by the rabbits. It is noteworthy that the total amount of the vitamin remaining in the caecum of the germfree animals was greater than that of $\mathrm{HEF}$ in the caecum of the corresponding conventional controls, possibly indicating some microbial destruction of the vitamin as well as its degradation to HEF. The question of the nutritional value of HEF to the rabbit remains unanswered. As Owen \& West (1970) pointed out, HEF can cover only a small fraction of the requirement for riboflavine of such widely disparate forms of life as the rat and Lactobacillus casei (ATCC 7469). It therefore seems very unlikely that HEF can cover more than a very small proportion of the rabbit's requirement of riboflavine though, so far as we know, no tests of the biological value of HEF or of mixtures of it with riboflavine have ever been made on the rabbit.

Another aspect of the current experiments merits discussion. The diet used was not of the type that enables an animal to obtain maximal benefit by coprophagy from the synthesis of B-vitamins in the hind-gut. Diets providing optimal conditions for such syntheses are rich in uncooked potato starch and are poor in cellulose (Hopkins \& Leader, I945-6), which our diets contained. Furthermore, when dietary fat replaces carbohydrate the animal's requirement for riboflavine is increased. This has been shown to be true for cats (Gershoff, Andrus \& Hegsted, 1959), guinea-pigs (Hara, 1960) and rats (Koyanagi \& Oikawa, 1965). Diets I, 2 and 3 were all designedly rich in fat because the animals were also being used for studies of fat metabolism.

Grateful acknowledgement is made for the technical help of Miss S. McLauchlin of the Hannah Institute and for skilful hand-rearing and management of the rabbits by Mr D. A. F. Miles of the National Institute for Research in Dairying. 


\section{REFERENCES}

Coates, M. E., Ford, J. E. \& Harrison, G. F. (1968). Br. J. Nutr. 22, 493.

Eden, A. (1940). Nature, Lond. r45, 628.

Eden, A. (1941). F. agric. Sci., Camb. 31, I45.

Fuller, R. (1968). In The Germfree Animal in Research, p. 37. [M. E. Coates, editor.] London and New York: Academic Press.

Gershoff, S. N., Andrus, S. B. \& Hegsted, D. M. (1959). F. Nutr. 68, 75.

Hara, H. (I960). F. Vitamin. 6, 24.

Hobson, P. N., Summers, R., Owen, E. C., Spencer, J. C. \& West, D. W. (1969). Proc. Nutr. Soc. 28, 53 A.

Hopkins, F. G. \& Leader, V. R. (1945-6). F. Hyg., Camb. 44, I 49.

Innami, S. \& Tezuka, T. (1965). Fap. F. Nutr. 23, 63.

Koyanagi, J. \& Oikawa, K. (I965). Tohoku F. exp. Med. 86, 19.

Kulwich, R., Struglia, L. \& Pearson, P. B. (1953). F. Nutr. 49, 639.

McElroy, L. W. \& Goss, H. (1941). भ. Nutr. 21, 405.

Moore, J. H. \& Williams, D. L. (1964). Br. F. Nutr. x8, 253.

Olcese, O., Pearson, P. B. \& Schweigert, B. S. (1948). F. Nutr. 35, 577.

Owen, E. C. (1962a). Proc. int. Congr. Fd Sci. Technol. I. London. Vol. 3, p. 669.

Owen, E. C. $($ r $962 b)$. Biochem. F. 84, $96 P$.

Owen, E. C. \& West, D. W. (I968). F. chem. Soc. (C) p. 34.

Owen, E. C. \& West, D. W. (I970). Br. F. Nutr. 24, 45.

Smith, H. W. (1965). F. Path. Bact. 89, 95.

Thacker, E. J. \& Brandt, C. S. (1955). F. Nutr. 55, 375.

West, D. W. \& Owen, E. C. (I969). Br. F. Nutr. 23, 889.

West, D. W., Owen, E. C. \& Taylor, M. M. (1967). Proc. Nutr. Soc. 26, xvii. 